\title{
CONTROL OF INVERTERS TO SUPPORT BIDIRECTIONAL POWER FLOW IN GRID CONNECTED SYSTEMS
}

\author{
Amakye Dickson Ntoni ${ }^{1}$ \\ ${ }^{1}$ ME Scholar, Power Electronics and Drives Engineering, Dept of Electrical and Electronics Engineering, College of \\ Engineering, Guindy, Anna University, Chennai -600025
}

\begin{abstract}
This paper discusses the usefulness of inverter to support bi-directional power flow in grid connected systems. The design includes a bidirectional inverter (single phase) along with a dc-dc converter interfaced with a battery bank or any renewable resources such as solar arrays, fuel cells etc. In this paper, battery bank is used when grid requires additional power to meet out load demand, battery operates in discharge mode and power is fed into the grid. When grid has surplus power, battery operates in charge mode and power is fed into the battery. During discharge mode, power is fed at unity power factor. The simulation studies are carried out with the help of MATLAB/SIMULINK. The hardware is implemented with Arduino Atmel 328 with an AVR microcontroller. The inverter designed is of high efficiency energy output, lower cost.
\end{abstract}

Keywords: Inverter, grid-tie inverter, microgrid

\section{INTRODUCTION}

As the population increases and people continue to demand a higher standard of living, the demand for energy also continues to increase. These demands give rise to a number of alternative power sources to support the traditional method of generation of energy. As it becomes necessary for alternative power sources such as fuel cells and photovoltaic systems in the distributed power system architecture, it is relevant to design, control and implement inverters to support seamless bi-directional power flow between the inverter and the grid connected systems. An inverter used to convert the DC voltages of the alternative power sources into utility grade $\mathrm{AC}$ voltages. In this paper the inverter discussed can be used as a rectifier to draw power from the grid to charge the batteries or supply other DC loads. In this way the inverter supplies power at unity power factor. The inverter in standalone operation mode are required to work in voltage control mode supplying effective, efficiency and quality power to any local load connected to it. However, in grid connected mode the inverter should operate in current control mode. The inverter should operate in power factor correction mode when drawing power from the grid. The two modes transfer need to be automatic and hence, smooth and seamless. In power factor correction-rectification mode the system designed filter inductance and the DC side capacitance is used to determine the system dynamics.

\section{SYSTEM DESCRIPTION}

Grid tie-inverter is a special inverter type that converts DC power to AC power. The grid tie inverter (GTI) are mostly used to convert DC power produced by renewable energy sources like fuel cells, wind turbine, solar array, into AC power used to power homes and industries. To be able to regulate power quality, dynamics and transient characteristics of power angle, frequency and voltage we need GTI that is able to control bi-directional active and reactive flowing to and fro from the network. In fig 1, the four numbered T!, T2, T3 and T4. The switches in each branch operate alternatively. Again they are not in the same ON or OFF mode simultaneously. Practically, both are OFF for a short period called blinking time. To avoid short circuiting, switches $\mathrm{T} 1$ and $\mathrm{T} 2$ or T3 and T4 should operate in pair to produce output. These bridges legs are switched in such a way that voltage is shift from one to another resulting in change of polarity which is depicted in voltage waveform. If the shift angle is zero, then the resulting output voltage is also zero but maximal the shift angle is $\pi$.

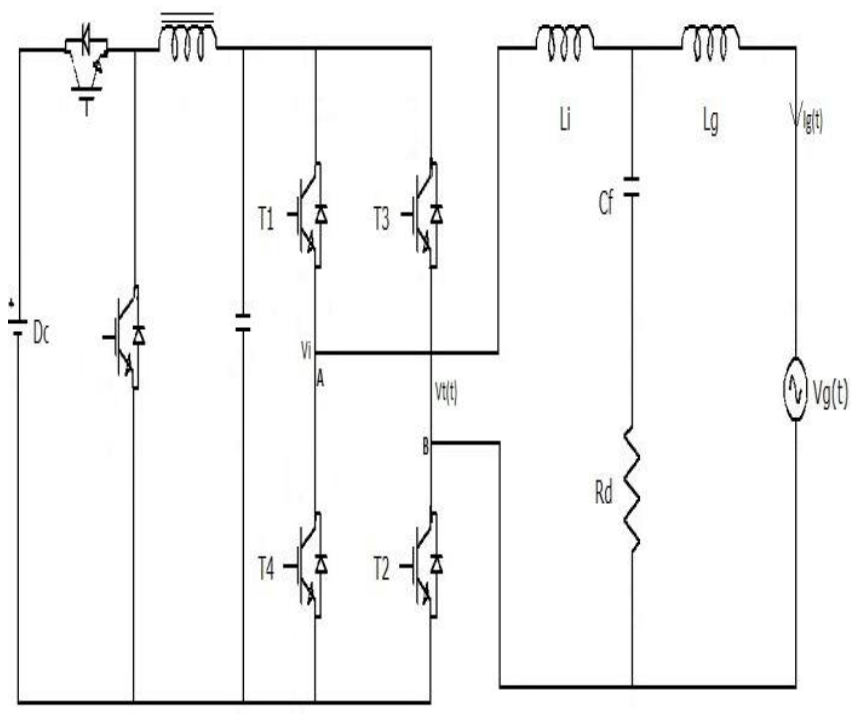

Fig-1: Power stage circuit configuration single phase PV full-bridge inverter. 
The reason of this full bridge single phase inverter is that it provides voltage across the inductor which in turns, generate current as express by the equation below:

$$
\mathrm{i}_{\mathrm{L}}(\mathrm{t})=\frac{1}{L} \int \mathrm{V}_{\mathrm{L}} d t+c
$$

Where VL and C represent the voltage the voltage across the inductor and the integration constant respectively

For low voltage application CSI voltage is not suitable hence additional buck converter is used. For minimizing CSI switching losses, new reverse blocking IGBT techniques are employed. [5], this reduces the power loss and increases efficiency of system.

HF link inverter is used between DC-DC converters. The inverter converts direct input voltage into an HFs square wave which is rectified and subsequently filtered using LPF low pass output is a high-level direct voltage that is converted into a low frequency wave.

The Fourier series output voltage of square wave inverter is given:

$$
V_{0}(t)=a_{0}+\sum_{n=1,3,5 . .}^{\infty}\left(a_{n} \cos n \omega t+b_{n} \sin n \omega t\right)
$$

Where

$$
V_{\mathrm{o}}(t)=\sum_{n=1,3,5 . .}^{\infty} \frac{4 V s}{n \pi} \sin n \omega t
$$

$$
\begin{aligned}
& a_{0}=a_{n}=0 ; \\
& b_{n}=\frac{4 V s}{n \pi}
\end{aligned}
$$

Therefore;

$$
V_{0}(t)=\frac{4 V s}{\pi}\left\{\sin \omega t+\frac{1}{3} \sin 3 \omega t+\frac{1}{3} \sin 5 \omega t+. .\right\}
$$

For modified square wave, the Fourier series output voltage is express as:

$$
V_{0}(t)=\sum_{n=1,3,5 . .}^{\infty} \frac{4 V s}{n \pi} \sin \frac{n \pi}{2} \sin n d \sin n \omega t
$$

\section{INVERTER SPECIFICATION}

The inverter specification is presented in th Table 1. As the design primarily focuses on the control and the grid synchronization method of the inverter, the efficiency target of the inverter is not specified because it is outside of the scope.

Table- 1: Inverter Specifications

\begin{tabular}{|l|l|}
\hline PARAMETERS & VALUES \\
\hline Nominal DC link Voltage $\mathrm{V}_{\mathrm{dc}}{ }^{\mathrm{n}}$ & $400 \mathrm{~V}$ \\
\hline Rated grid voltage $\mathrm{V}_{\mathrm{g}}$ rated & $250(\mathrm{RMS})$ \\
\hline Switching frequecy $\mathrm{f}_{\mathrm{SW}}$ & $10-45 \mathrm{KHZ}$ \\
\hline Rated grid current $\mathrm{I}_{\mathrm{g}}^{\text {rated }}$ & $10 \mathrm{~A}$ \\
\hline $\begin{array}{l}\text { Percentage } \mathrm{DC} \text {-link voltage ripple } \\
\text { (peak to nominal) }\end{array}$ & $10 \%$ \\
\hline $\begin{array}{l}\text { Phase diference between the grid } \\
\text { and reference current, } \phi\end{array}$ & 0 \\
\hline Bridge side inductor $\mathrm{L}_{\mathrm{i}}$ & $300 \mathrm{uH}$ \\
\hline Filter capacitor $\mathrm{C}_{\mathrm{f}}$ & $30 \mathrm{uF}$ \\
\hline Filter damping resistor $\mathrm{Rd}$ & $1.5 \Omega$ \\
\hline
\end{tabular}

Assuming the grid voltage and the grid current are:

$$
\begin{gathered}
V g(t)=\tilde{V} g \cos (\omega g t) \\
\operatorname{Ig}(t)=\hat{I} g \cos (\omega g t-\varphi)
\end{gathered}
$$

Then the instantaneous output power can be easily obtained as:

$$
\begin{aligned}
& \text { Pout }(t)=\tilde{V} g \hat{I g} \cos (\omega g t) \cos (\omega g t-\varphi) \\
& =\tilde{\text { VrmsÎtgrms }}+\tilde{\text { VrmsÎIrmscos }}(2 \omega \mathrm{gt}-\varphi)
\end{aligned}
$$

This can be rewritten to be:

$$
\text { Pout }(\mathrm{t})=\mathrm{S} \cos \varphi+\mathrm{S} \cos (2 \omega \mathrm{gt}-\varphi)
$$

Where S denote apparent power which has a unit of VA

\section{COMPUTER SIMULATION}

The simulation tool used is MATLAB/SIMULINK. The DC/DC converter converters the non constants dc voltage coming from the renewable sources into a constant $24 \mathrm{~V} \mathrm{DC}$ voltage and subsequently supply it to the inverter. The inverter then converts this DC voltage to AC and feed to the grid at unity power factor. Initially Single phase inverter is designed with Resistive load is shown in fig-3.

The closed loop simulation is also realized 


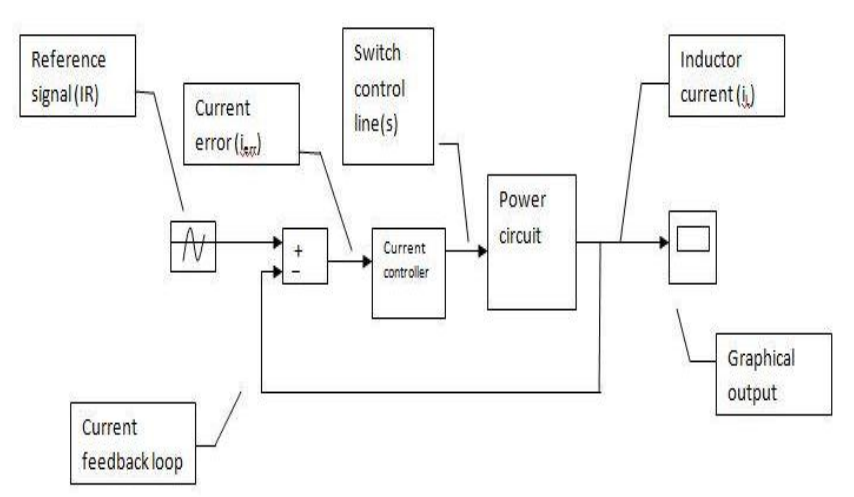

Fig-2: Structure of Matlab/SimulinkSimulation

The current output il from the circuit is compared with the reference signal for which current error icr is generated. The switch control logic is produced when current error signal icr is fed to the current control block. The output current is controlled by the power circuit connected to it by the switch control lines.

The different simulation values are defined by the following equation:

$$
\begin{array}{r}
\mathrm{Vg}=\mathrm{A} g \sin (2 \pi \mathrm{fg} \mathrm{t}) \\
\mathrm{VR}=\mathrm{A} R \sin (2 \pi \mathrm{fRt}+\phi)
\end{array}
$$

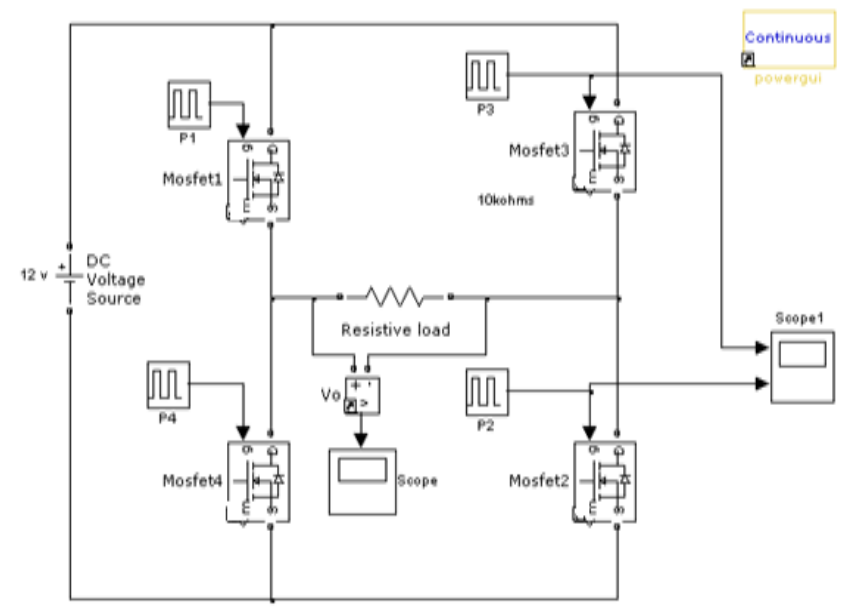

Fig-3: Single phase inverter modeling

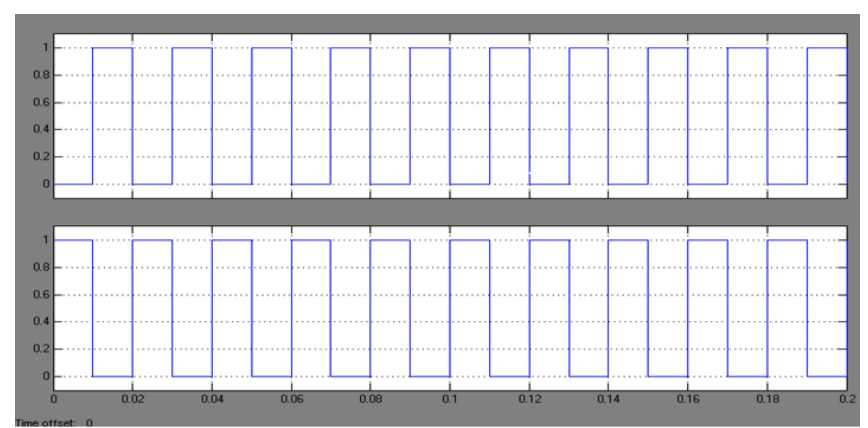

Fig-4: Gate pulses for MOSFET

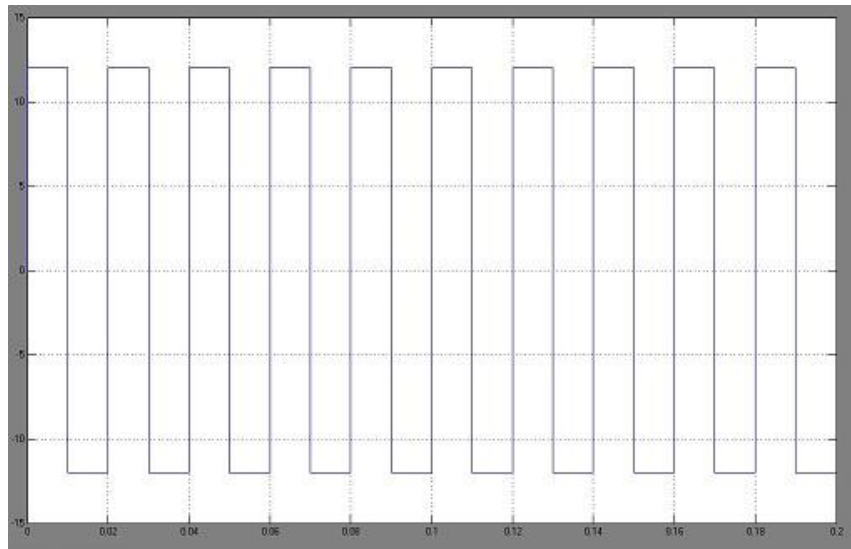

Fig-5: Inverter with Resistive load

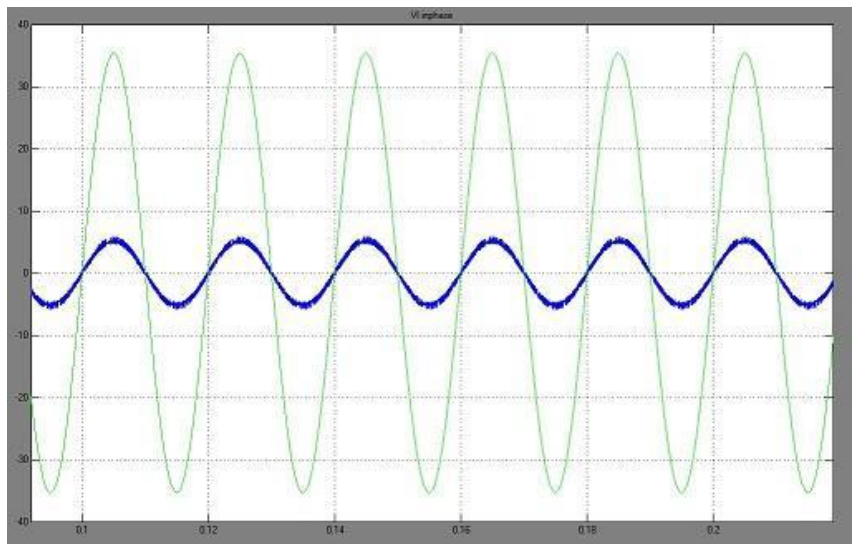

Fig-6: Grid voltage and current waveform

\section{HARDWARE DESCRIPTION}

The overall hardware setup is shown in fig-8. DC-Dc convreter is fed from a fluctuating Dc source to be converted to fixed Dc value of $24 \mathrm{~V}$. this falls to be the input for the inverter. The H-bridge inverter is made up of four IRF40 nMOSFET(n-channel enhancement). Th MOSFET witches are rated for $60 \mathrm{~V}-100 \mathrm{~V}$ for voltage and $27 \mathrm{~A}$ for current, with fast switching time of 25 nanoseconds for rising time and 25nanoseconds for falling times. The switches have high efficiency with less power disipation.

The IFR540 MOSFET switche are driven using IR2110 drivers. The PWM gate pulses to drive the MOSFET are generated using Arduino ATmega 328 microprocesor which turns at a clock peed of $16 \mathrm{MHz}$. The transistors and OpAmps are used to convert two PWM signals comin from the arduino microcontroller into four signals to drive the MOSFET. Electrical isloation of power electronics voltage circuits were done with the aid of optocoupler 6 N25. The inverter is connected to an inductor and capacitor. The cut off frquency of the LC filter is given by:

$F_{\mathrm{c}}=\frac{1}{2 \pi \sqrt{L C}}$

For $\mathrm{L}=37 \mathrm{mH}$ and $\mathrm{C}=2.6 \mu \mathrm{F}, \mathrm{Fc}=513 \mathrm{~Hz}$ 
The resulting output impedance $(\mathrm{Z})$ of the filter is given by

$$
Z=\frac{1}{2 \pi \sqrt{f c c}}
$$

With the same values for $\mathrm{L}$ and $\mathrm{C}, \mathrm{Z}=4.26 \Omega$

In order to improve the output waveform of the grid and to maximize the power transfer to the grid, a damping resistor is connected in parallel with the capacitor to match the input impedance of the grid.

The inverter is used tracks both the phase and frequency of the grid waveform. The tracked waveform is used to generate output signals to drive the H-bridge's low and high side switches.

The hardware interface architecture sketch is presented in fig. 9

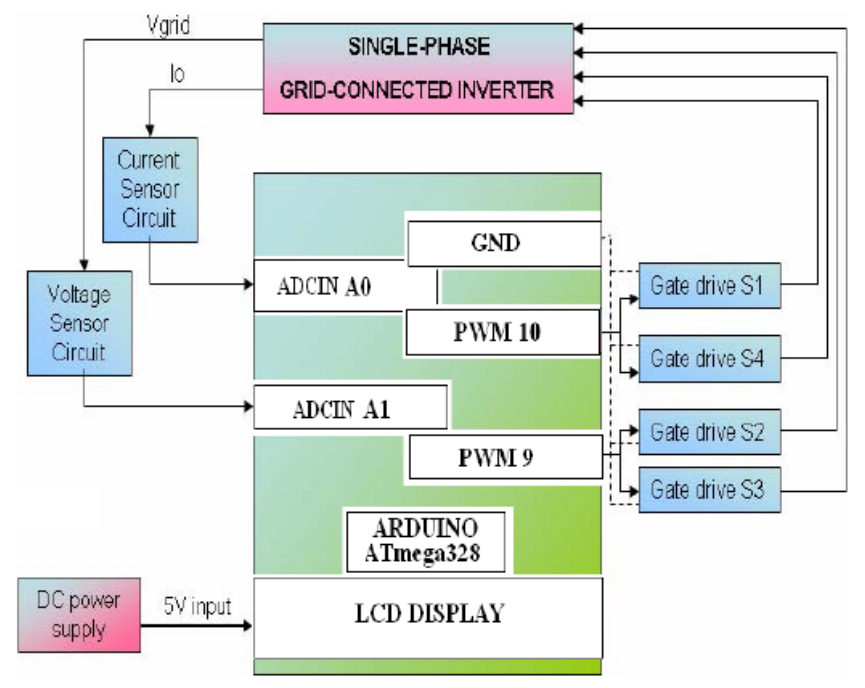

Fig-7: Hard ware interface Architecture

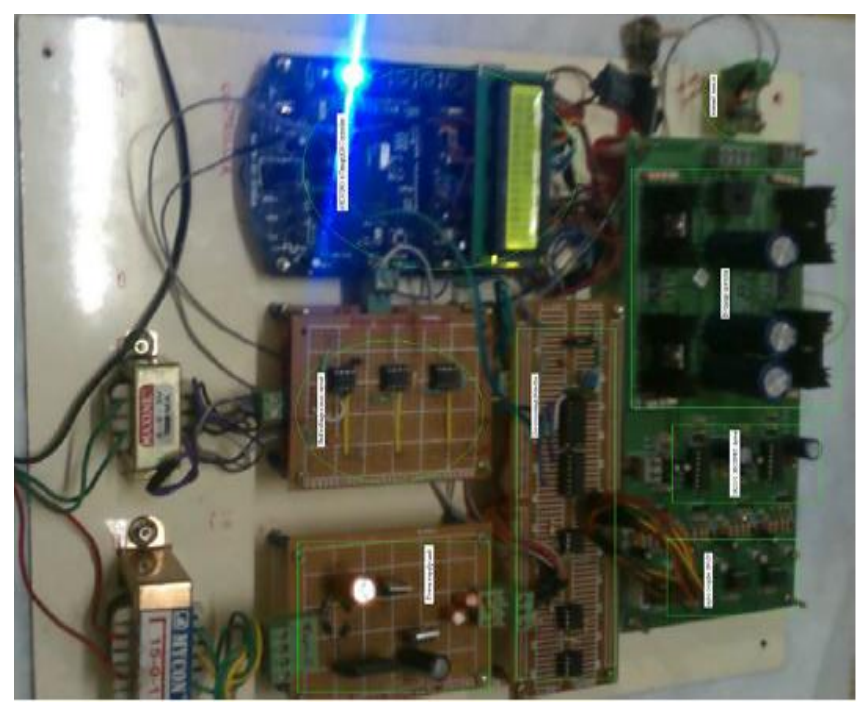

Fig-8: Hardware setup

\section{RESULTS AND DISCUSSION}

The basic open loop simulation of single phase inverter is shown in Fig 3. It contains four number of MOSFETS switches. When alternatively conducts one upper MOSFET and one bottom MOSFET. All the gates are triggered by an external clock pulses. The total time period of all pulses are equal, like $\mathrm{T}=0.2 \mathrm{sec}(\mathrm{f}=50 \mathrm{~Hz})$. When combination of MOSFETS 1,2 and MOSFETS $3 \& 4$ are conducts alternatively. During 1st half of time MOSFETs 1and 2 are conducts and next half cycle MOSFETs 3 and4 conducts. In this combination provides the inverter output is either $+\mathrm{Vs}$ or $-\mathrm{Vs}$. The gating pulses and inverter output waveforms are presented in fig 4 and fig 5 respectively. The grid voltage and current is shown fig- 6 inferring UPF operation. Since the voltage and current is in phase, the power factor is close or at unity. Fig 9 shows the hardware pulse for MOSFET and the overall hardware setup is shown in fig- 8 . The steady state response of the inverter under both standalone mode and inverter responds showing the power reversal between the grid and the inverter-rectifier is shown in fig-11 and fig12 respectively. Time scale is $5 \mathrm{~ms}$ per division; Grid voltage scale is $100 \mathrm{~V}$ per division and inverter current is $20 \mathrm{~A}$ per division.

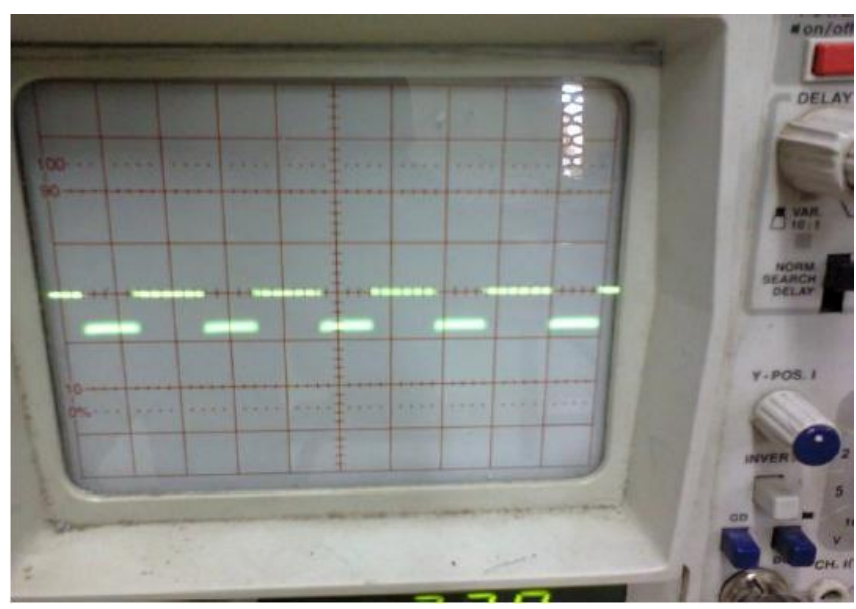

Fig-9: PWM Waveform

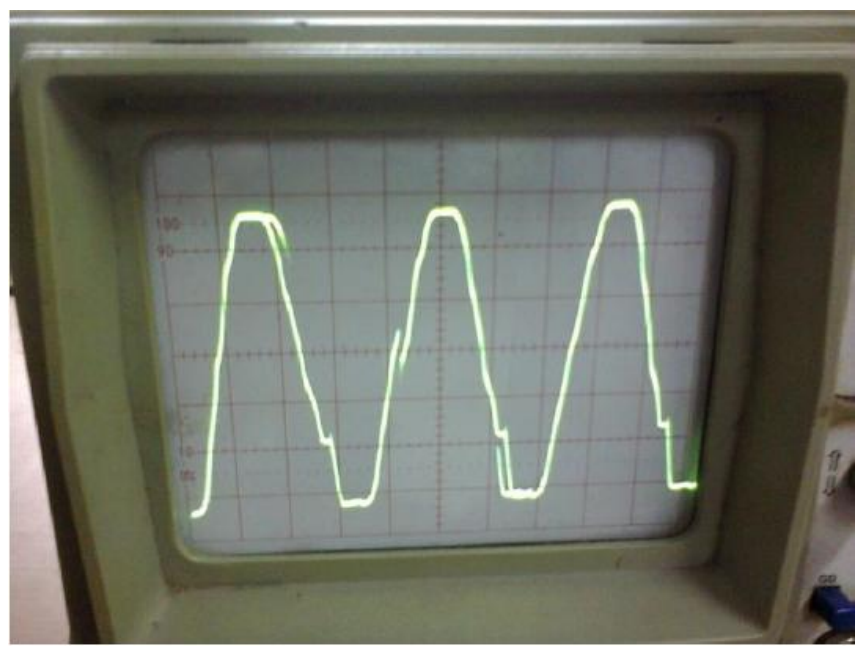

Fig-10: Inverter with RL load 


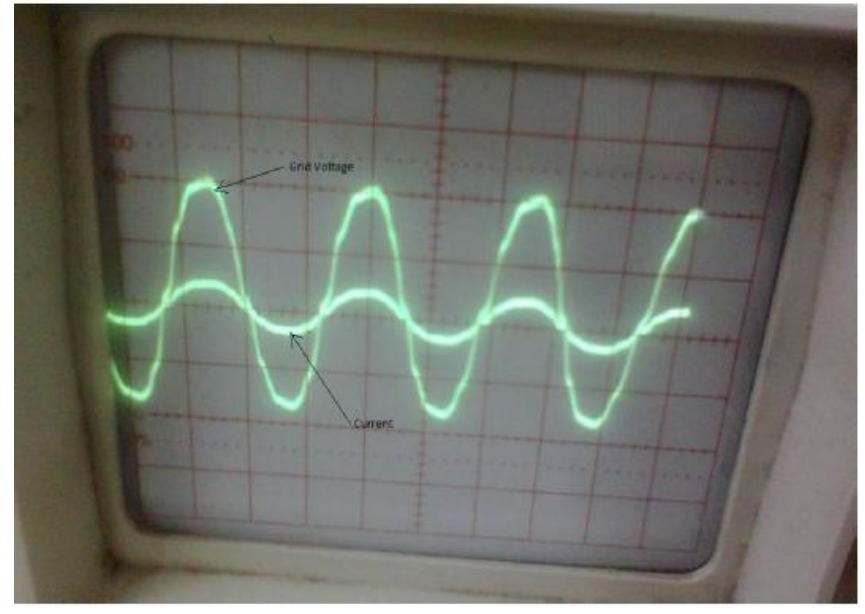

Fig-11: Grid voltage and current output.

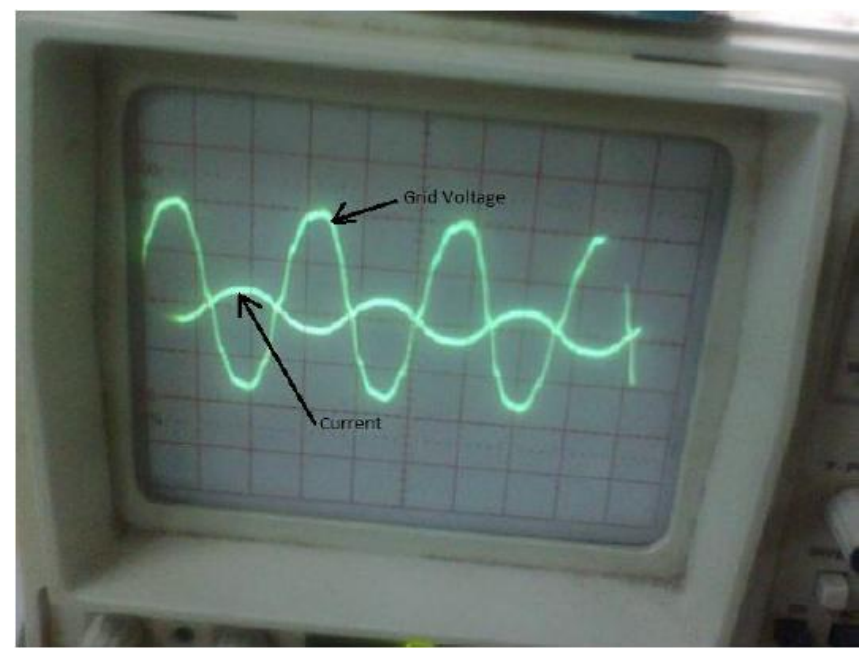

Fig-12: Inverter response showing power reversal between grid and inverter-rectifier.

\section{CONCLUSIONS}

Design of inverters to support bidirectional power flow in grid connected inverter systems has been presented. The frequency, amplitude and phase the inverter output signal are synchronizing with that the grid voltage signal. An arduino Atmel microcontroller is used to control the single phase inverter switches. It is deduced that the grid tied inverter is able to produce an Ac waveform which is synchronized with the grid.

The setup is capable of controlling both the inverter's real and reactive power output. The LC filter of the inverter is capable of removing most the noise, and provides better filter structure required for smooth output waveforms

\section{REFERENCES}

[1]. D.M. Baker, V.G. Agelidis, C.V. Nayer, "A comparison of tri-level and bi-level current controlled grid-connected single-phase full-bridge inverters", ISIE '97. Proceedings of the IEEE International Symposium on Industrial Electronics, Volume: 2, 1997, page(s): $463-468$.
[2]. IOANNIDIS, G., XANTHOULIS, E., and MANIAS, S.N.: 'A novel uninterruptible power supply system with sinusoidal input-output characteristics and simplified control circuit'. Proceedings of the IEEE International Symposium on lndustdal electronics, 1995, Vol. 2, pp.

[3]. D.H. Moore, H.M. Abdar, A. Chakraverty, J.M.Murray, K.A. Loparo, Grid of the Future Laboratory Demonstration System, Submitted to Energy Tech 2012 Conference.603609

[4]. Klumpner, C. "A New Single-Stage Current Source Inverter for Photovoltaic and Fuel Cell Applications using Reverse Blocking IGBTs." Power Electronics Specialists Conference, 2007. PESC 1683 -1689, IEEE 2007

[5]. BOSE, B.K., SZCZESNY, P.M., and STEIGERWALD, R.: 'Micro- computer control of a residential photovoltaic power conditioning sys- tem', IEEE Trans. Ind. Appl., IEEE Trans. Ind. Appl., 21, [5], pp.1182-1191

[6]. HORTA, H.S., and CARDENNAS, G.V.M.: 'DC-AC converter with high frequency DC link for UPS applications'. Proceedings of the 3rd International Conference on Power electronics, 1994, pp. 125-130

[7]. Carbone, R., "Grid-connected photovoltaic systems with energy storage". In Clean Electrical Power, 2009 International Conference, 760-767

[8]. A.Nachiappan, K.Sundararajan, V Malarselvam, "Current controlled voltage source inverter using Hysteresis controller and PI controller", IEEE Int. Conf. on Power, Signals, Controls and Computation (EPSCICON), pp.1-6, 20129.

[9]. Philip P. Barker, James M. Bing, "Advances in Solar Photovoltaic Technology: An Applications Perspective", Power Engineering Society General Meeting, IEEE, pp. 1955- 1960 Vol. 22005.

[10]. Feng Gao, Chao Liang, Poh Chiang Loh, Frede Blaabjerg, "Buck-Boost Current-Source Inverters With Diode-Inductor Network", IEEE Transactions On Industry Applications, Vol. 45, No. 2, March/April 2009.

[11]. F. Flinders, S. Senini and W. Oghanna, "Power electronic Simulation laboratory using "Simulink" Dynamics Systems Analysis Package, ZMACS, July1993, pp643-650

[12]. M.H.Rashid, "Power Electronics Circuit Device and Application", 3rd Ed. New Delhi, India, Pearson Education, 2011, pp. 352-430

\section{BIOGRAPHIES}

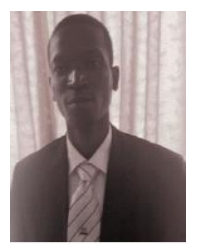

Amakye Dickson Ntoni received the B.E degree in ECE from All Nations University College, Koforidua, Ghana-West Africa. He is currently pursuing ME Power Electronics and Drives in Electrical Dept. at Anna University (CEG) India. His interests are wireless communications, power converters and inverters. He also has interest in power systems analysis and control. 